\title{
Seasonal Variations of Aerosol Optical Properties and Identification of Different Aerosol Types Based on AERONET Data over Sub-Sahara West-Africa
}

\author{
Mukhtar Balarabe ${ }^{1,2 *}$, Khiruddin Abdullah1, Mohd Nawawi1 \\ ${ }^{1}$ School of Physics, University Sains Malaysia, Pulau Pinang, Malaysia \\ ${ }^{2}$ Hassan Usman Katsina Polytechnic, Katsina, Nigeria \\ Email: *mab13_phy006@student.usm.my
}

Received 19 October 2015; accepted 5 January 2016; published 8 January 2016

Copyright (C) 2016 by authors and Scientific Research Publishing Inc.

This work is licensed under the Creative Commons Attribution International License (CC BY). http://creativecommons.org/licenses/by/4.0/

(c) (i) Open Access

\section{Abstract}

The uncertainty in the quantification of aerosol properties such as concentration, size, and composition, spatially and temporally makes regional studies important. Therefore, this study presents seasonal variations of aerosol optical properties over Ilorin $\left(8^{\circ} 32 ' \mathrm{~N}, 4^{\circ} 34\right.$ ' $\left.\mathrm{E}\right)$, Nigeria. Long-term (1998-2013) records of aerosol optical depth (AOD) and angstrom exponent $\alpha$, from ground-based Aerosol Robotic Network (AERONET) are used to study the seasonal variability, characteristics and types of aerosol. The study showed that seasonal variations (Harmattan and Summer) result in different aerosol concentration, characteristics, and types. The magnitude and sensitivity of AOD to wavelength are found low in Summer with significant increase during Saharan dust transport season (Harmattan). The average mean AODs are $0.73 \pm 0.50,0.97 \pm 0.52$ and $0.46 \pm 0.29$ with corresponding mean angstrom of $0.66 \pm 0.36,0.68 \pm 0.34$, and $0.64 \pm 0.37$ for the entire period, Harmattan and Summer seasons. High frequency of occurrence of angstrom exponent below 1 (78\% and $81 \%$ ) which were observed during Harmattan and Summer indicates that the particles are generally coarse in mode. The results revealed that for both Harmattan and Summer seasons, the dominant aerosol was dust (DA) with frequency of occurrence of $82 \%$ and $79 \%$. However, mixed aerosol (MIXA) (14.4\%) is the second dominant case during Harmattan while in Summer maritime aerosol (MA) (9.1\%) associated with transport due to southwesterly trade wind is the second dominant aerosol. This conclusion is supported by size distribution data for the study site which showed that large volume of aerosol particle size are enclosed in largely coarse mode range in all seasons. A 7-day back trajectory seasonal frequency plot sourced from the Hysplit Single Particles Lagrangian Integrated Trajectory model (Hysplit_4 model) shows that dust are transported from the Saha-

\footnotetext{
${ }^{*}$ Corresponding author.
} 
ra during north-easterly trade wind flow while the observed marine aerosols are conveyed by the southwesterly trade wind influences to the study site.

\section{Keywords}

\section{Aerosol, Angstrom Exponent, Harmattan, Optical Depth, Summer}

\section{Introduction}

Aerosols are tiny (micro and submicron) sized particles (solid or liquid) that are suspended in the atmosphere [1]. They are made of mixture of different substances such as dust, smoke, organic matter, gas pollutants and airborne particles. Aerosols are injected into the atmosphere from both natural and anthropogenic sources [2] such as freezing of water vapor, condensation, dust storm, biomass burning, volcanic eruption, digging of soil through farming and irrigation, forest fire, vegetation, secondary inorganic salts, and sea spray. They are distributed in the atmosphere by turbulence and regional/global circulation (i.e. movement of air masses). Aerosols are removed from the atmosphere by precipitation, ice, dew and other forms of precipitations. They can also be removed through dry sedimentation (under the influence of gravitational force). The concentrations and distribution of aerosols in the atmosphere are highly variable in space and time. It depends upon factors such as location, seasons, atmospheric conditions, annual and diurnal cycles and the presence of local sources.

Due to position of Nigeria in sub-Sahara West Africa, aerosol pollution is a familiar phenomenon of which its concentrations exhibit strong seasonal variability mainly driven by seasonally changed air mass (northeasterly trade wind and southwesterly trade wind) patterns during Harmattan (November-March) and Summer (AprilOctober) seasons [3]. The two main seasons not only dictate variations in concentrations, but also types, and distributions of aerosols both spatially and temporally. During Summer, Nigeria generally experiences heavy and continuous rainfall at different magnitude from one region to another which is believed to reduce the concentration aerosol load from the atmosphere. However, during the Harmattan season, dust is normally transported from the Sahara, as well as from neighbouring sources in the sahel and local emission [4]. In addition, smoke aerosols are produced in large quantity, owing to land clearing for upcoming farming activities, and need for warm weather. These activities produce aerosols mainly of anthropogenic origin that increase the aerosol concentration in the atmospheric column.

The increases in aerosol particles in the atmosphere are reported to affect transmission of solar radiation through scattering and absorption [3] which has both direct and indirect consequences on the earth climate. It also directly leads to visibility degradations [4]-[6] which in turn affect region's economy. Furthermore, aerosol concentration in the atmosphere has also been reported to affect air quality and human health [7] [8]. Aerosol causes indirect effect by increasing cloud condensation nuclei and consequently to larger concentrations of cloud droplet with small radii [9]. It is established that quantifications of these effects become difficult due to their types (as a result of their variety of sources), varying pattern and interaction among each other [10] [11]. To minimise this uncertainty, many scientist are involved in constant monitoring of their concentration and effect at global and regional scale [1] [5] [10] [12]-[14]. This is possible through measurements of aerosol optical and physical properties at global and regional scale. Some of these measurements are ground-based, aircraft or satellite with different temporal scales. Aerosol Robotic Network (AERONET) data is considered more reliable for local/regional aerosol study compared to satellite. Satellite observations, however, have the capability of providing global scale coverage of aerosol optical properties compare to AERONET which is limited to space coverage [15], as a result, many studies on aerosol optical properties [2] [15]-[19] have been conducted using AERONET sunphotometer or sky radiometer [20].

Understanding the aerosol trend pattern, variability, types and dominant aerosol in a particular region and time is therefore essential to help improve the accuracy of aerosol prediction models at a regional level. It can also make the determination of the effect of each aerosol in the atmosphere easier [2]. This study is essential in Nigeria because of the rapid increase in population density and economic growth that has given rise to increase anthropogenic emission at different rate, sources and region. Variation in the weather pattern as reported by Balarabe et al. [4] is believed to be responsible for increase local emission rate and transport. This study is there- 
fore aimed at analyzing the optical properties, characterizing and discriminating different aerosol types over Ilorin Nigeria.

Different criteria have been proposed by different authors [17] [19] [21]-[24] in different regions of the world to classify aerosols. Fuyi et al. [15] [16] employed criteria suggested by some of these authors [17] [19] [21]-[24] to classify aerosol as well as analyzed the sensitivity of each criteria to aerosol discriminations in south-east Asia. According to the authors, the result based on the criteria provided by [21]-[24] may not be applicable in Malaysia and therefore, conclude that the threshold provided by Toledano et al. [19] is typical for their study site. Ogunjobi et al. [20] applied the criteria proposed by Pace et al. [22] in our study region to discriminate different aerosol types during and after a specific dust event in December 1998, January 2000 and 2005 as well as March 2003, in which variations in aerosol optical depth, angstrom exponent and turbidity parameter during the events were also analyzed. A fitted Gaussian models to the AOD and angstrom exponent was used to study the seasonal characteristics of spectral aerosol optical properties in this site [3]. The authors also used probability densities of AOD and angstrom exponent from 1998 to 2002 and 2003-2008 as the means of analyzing aerosol variability. In this study, a long-term seasonal variability of aerosol optical properties are analyzed as well as classified using criteria proposed by Toledanos [19] with the view of identifying the dominant aerosol types and their frequencies. This study is the first of its kind that analyzed the long-term monthly variations and seasonal frequency of different aerosol types over West-African region. The study also employed Hyslipt model to further identify the sources of aerosol being transported into Nigeria during Harmattan and Summer seasons.

\section{Methodology}

A ground-based AERONET sun photometer sensors are situated at the AERONET observation site located in Ilorin on latitude $8^{\circ} 32^{\prime} \mathrm{N}$ and longitude $4^{\circ} 34^{\prime} \mathrm{E}$, Nigeria; detail description of the study site can be found in Nwafor et al. [3] and Ogunjobi et al. [9] while the instrument was described in detail by Holben et al. [20]. Direct sun-photometer measures solar attenuation and sky brightness every 15 minutes at 340, 380, 440, 500, 675, 870, 940, and $1020 \mathrm{~nm}$ (including the $1640 \mathrm{~nm}$ channel in Cimel version 5). This measured solar extinction are then used according to AERONET algorithm to compute AOD at each wavelength except for channel $940 \mathrm{~nm}$ which is used to retrieve precipitable water (PW) in centimeters. Angstrom exponent $(\alpha)$ can be retrieve from spectral AODs data [25] as an alternative to the usual way of computing $\alpha$ on two wavelengths as used in Nwafor $e$ al. [3], where the authors plotted the AOD against wavelength in log space and then made a linear fit of the data retrieved for the needed $\alpha$. The AERONET aerosol optical properties data from level 2 (cloud screen and quality assured) were used in this study. From which the long-term (1998-2013) daily average data were obtained. The large data density for the period makes it easier for monthly cycle and distribution trends of AOD to be distinguished. Some gaps exist in the trends due to the absence or limited observations resulted from cloudy/rainy season and calibrations protocols [21]. The daily data were used to compute monthly, annual and seasonal means over the entire period of study. The dataset was divided into two groups based on the seasonal variations as used in some literatures [4]-[6] as follows: 1) November to March (Dry/Harmattan season); 2) April to October (Rainy/Summer season). The overall data over the entire study period were also analyzed.

To present the monthly cycle of aerosol concentration for the study site, AOD values at all spectral wavelengths (340 - $1020 \mathrm{~nm}$ ) were used to cover the solar spectrum. Subsequently, the monthly data of AOD_440, $\alpha \_440-870$, and PW water were analyzed to reveal the temporal variability of aerosol properties under moist and dry condition. The overall and seasonal frequency distribution pattern of the aerosol optical properties were identified by analyzing spectral AOD_440 and 870 as well as $\alpha 440$ - 870 as used by Toledano et al. [19]. The frequency distribution patterns of PW (in 440 - 870) revealed the amount of water content in atmospheric column during the distribution pattern of the aerosol properties. The above optical properties were quantitatively identified according to the scatter plots of the angstrom exponent $\alpha 440$ - 870 against AOD_440 and 870 and were used for classification based on the proposed criteria by Tolenado et al. [19]. The distribution patterns of different aerosol over the study region for the overall and seasonal data were determined. This criterion was applied to determine the aerosol types for different months throughout the year.

The overall and seasonal cycle of aerosol volume size distribution over the study period were analyzed to ascertain the volume of each aerosol class. The seven-day back-trajectory frequency seasonal plot by the Hybrid Single-Particle Lagrangian Integrated Trajectory (HYSLIT_4) model [26] was used to describe the aerosol sources because of its suitability to simulate air-mass movement. 


\section{Results and Discussion}

\subsection{Aerosol Climatology of Ilorin, Nigeria}

The annual cycle of AODs, $\alpha 440$ - 870, and PW in the atmospheric column measured between April 1998 and December 2013 for the study station are shown in Figure 1. The figure shows the usual trend of higher AOD at shorter solar wavelengths compared to that at longer wavelengths in all seasons. This can be attributed to the fact that at all seasons, the dominant aerosol particles in the atmosphere are more influentials scattered within a shorter wavelengths than at longer wavelength [3]. It also revealed large differences in the rate at which AOD increases/decreases at different wavelength and season. Thus, from November to December, AOD_340 increase by $52 \%$ while AOD_1020 increases by $27 \%$ which imply strong presence of coarse particles (dust aerosol) in the atmosphere during the period with large effect on AOD_340. From April to May (the onset of rain), AOD_340 decreases by $26 \%$ while AOD_1020 decreases by $25 \%$. This means that even though aerosol concentrations may vary, dust could be the dominant aerosol in this region irrespective of the season. Larger differences in the AOD values from one wavelength to another exist during Harmattan compared to Summer. This is due to large AOD variability as a result of different emission rate favored by local wind at the source [4].

It is clear from Figure 1 that, AODs present roughly high values with the same trend pattern regardless of the wavelengths that are the characteristics of desert dust event. A strong seasonal variation in the monthly trend at each wavelength is also observed. The lower AOD values occur in Summer and increases significantly during Harmattan. This cycle starts in October, when aerosol concentration begins to build up in the atmosphere, it increases continuously, depicting two peaks in January and March. The peak of lower wavelength AOD from 340 - 500 is observed in January while the longer wavelengths AOD (675 - $1020 \mathrm{~nm})$ attains its peaks in March with

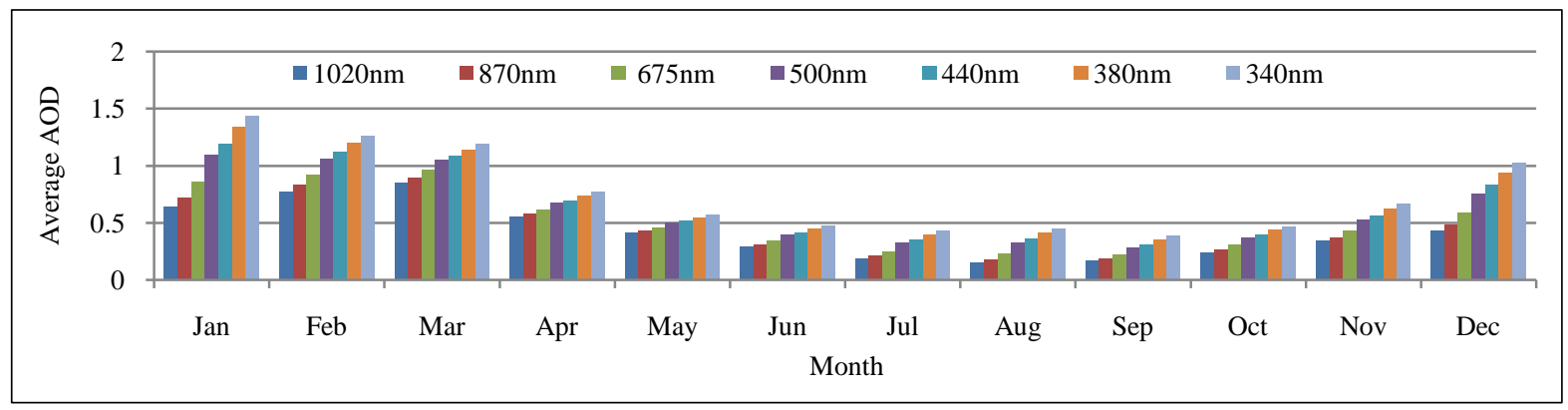

(a)

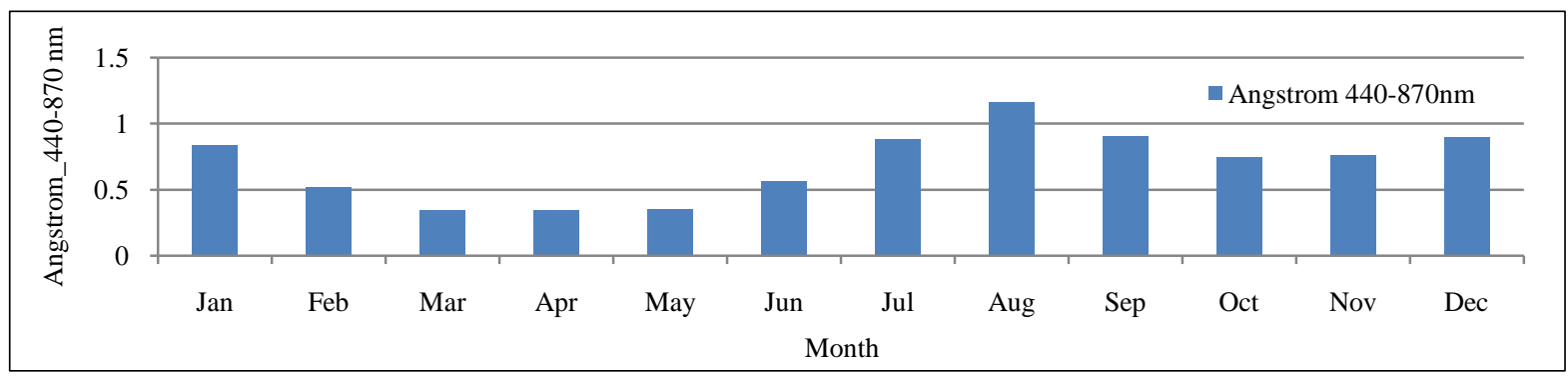

(b)

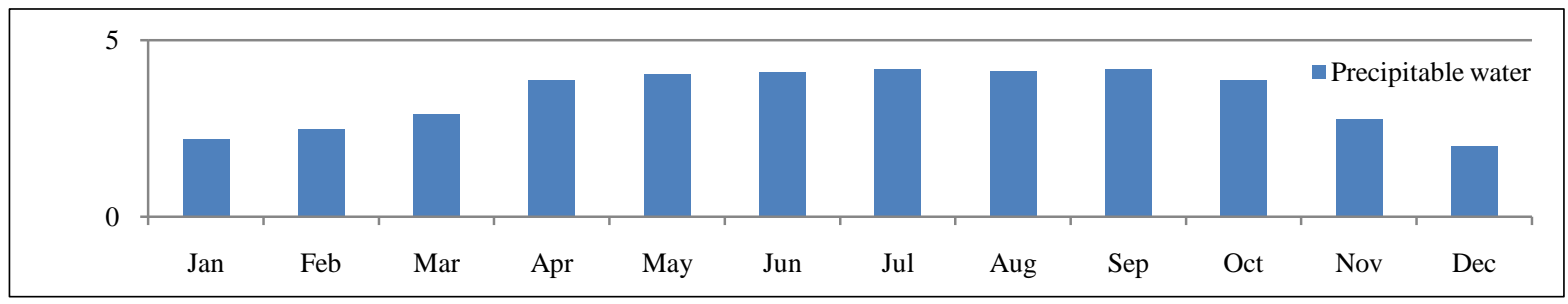

(c)

Figure 1. Monthly cycle of average AODs, angstrom exponent and precipitable water for 1998-2013. 
lower values from April to October. This low AOD in conjunction with high $\alpha 440$ - 870 values indicate the presence of aerosol species other than dust probably of maritime, biomass burning, or continental origin. AOD is lowest in September compared to other months. These patterns of monthly cycle of AOD (increase after Summer and decrease after Harmattan) remain consistent during the 16 years of study. These patterns are similar to the observed cycle of Aerosol Index for southern zone of Nigeria reported in [4].

The observed seasonal variation/pattern can be associated with high concentrations of coarse mode aerosol during Harmattan. These phenomena are observed at AOD_1020 which increases by $44 \%$ from the end of Summer (September) to the beginning of Harmattan (October) against smaller increased (21\%) for AOD_320. The conclusion is based on similar findings by Kaskoutis et al. [21] and is supported by the observed low $\alpha$ values, 0.35 in March to 0.89 in December, considering the dry condition (low PW) of the period as shown in Figure 1(b) and Figure 1(c). The transport of coarse particles (dust aerosol) from the Sahara to the study site by northeasterly Harmattan wind during Harmattan has been reported [4]. The seasonal dependence of AOD has resulted in the corresponding seasonal feature of angstrom exponent discussed below. The lowest values of mean $\alpha$ observed between March and May is a signature of mineral dust [9]. It increases from May until the peak is reached in August due to large and frequent rainfall [27] as a result of which significant amount of the larger particles are washed down from the atmosphere. The moist condition of this season can clearly be seen in figure 1C in the form of PW content. Angstrom remains considerably high in September and maintains almost constant values between October and November before another rise from December to January. PW variability can be explained by the movement of South-westerly moisture wind from Atlantic Ocean and North-easterly dry wind from Sahara. South-westerly trade wind comes with rain as a result of significant amount of coarse mode aerosol are being removed and deposited at the ground, thus angstrom exponent becomes larger. The sharp decrease of PW is noted when the North easterly wind blows from Sahara, resulting in large concentrations of coarse mode aerosols with low angstrom values.

Based on inter-comparison, the monthly AOD values obtained are higher than those reported by Nwafor $e$ al. [3] where the authors analyzed 6-years (1998-2003) AOD data from the same study region. We found that in each month, AOD_440 over Nigeria is higher than those in Huelva Spain [19]. Moreover, the mean AOD_500 values over this site are also greater than those in Penang Malaysia, except for August and September [16]. This is associated to large-scale open burning activities in Sumatra and Indonesia that favours transport of smoke [15]. The high AOD values in Nigeria may be explained by the fact that Nigeria is located in sub-Sahara West Africa where dust aerosol is regularly transported toward the Atlantic Ocean. Ilorin, the study area can be said to have poor air quality all year round for having the minimum monthly AOD_440 of 0.36 . According to Toledano et al. [19] the average AOD_440 values under clean background condition should be less than 0.05 .

\subsection{Temporal Analysis for AOD, Angstrom Exponent and Precipitable Water}

Figure 2 display monthly average AOD_440, angstrom (440 - 870) and precipitable water for the study period. The figures show significant monthly fluctuations in all the parameters influenced by a number of factors such as meteorological condition, anthropogenic emissions and dust transport associated with movement of air masses [12]. Within the study period, the Harmattan season is characterized by dry weather (low PW) (Figure 2(c)). Thus giving rise to long-range transport of dust by Harmattan wind, local dust emission, and active fire activities. As a result of this, the atmosphere has experienced a high level of pollution (Figure 2(a)) than Summer season. During Summer, rainfall is generally high and frequent (high PW) [27] Figure 2(c), large amount of aerosol is washed down consistently resulting in low AOD values. Also observed are consistent peaks in the AOD distribution during the Harmattan months due to the seasonal pattern of aerosol emission and transport leading to a considerable number of dessert dust activities. During the peak months, AOD is generally above 1 indicating that high turbidity episodes are very common in Nigerian atmosphere. There are no remarkable monthly trends for the entire period detected except in angstrom exponent (Figure 2(b)) where slightly increasing trend is observed.

There is also a significant year to year variability in the aerosol properties as revealed in Table 1. Even though, the computed daily and monthly mean values and ranges are also highlighted. The AOD_440 from the overall data series ranges from 0.05 to 3.86 on a daily basis. The overall, Harmattan and Summer seasons AOD averages are $0.73 \pm 0.50,0.97 \pm 0.52$ and $0.46 \pm 0.29$. The monthly mean varies from 0.23 to 1.50 . These high monthly averages of AOD (above 0.2) showed the level of pollution in the atmosphere consistently over an extended period 


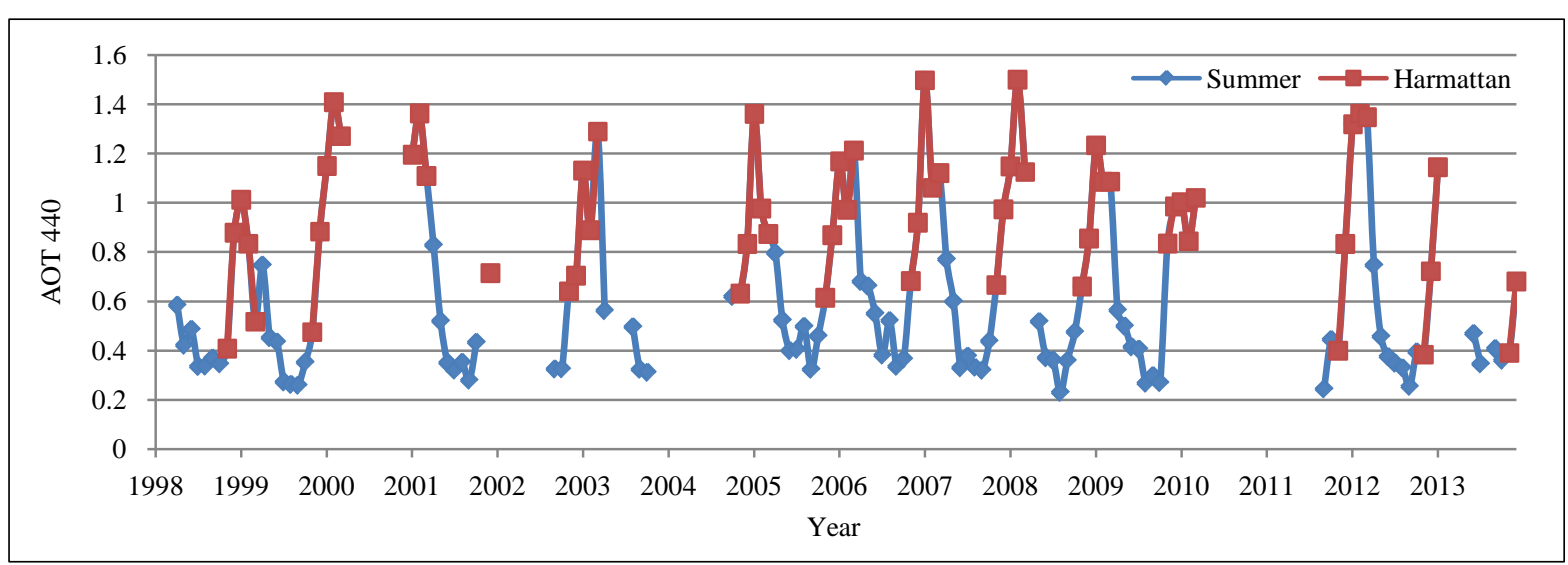

(a)

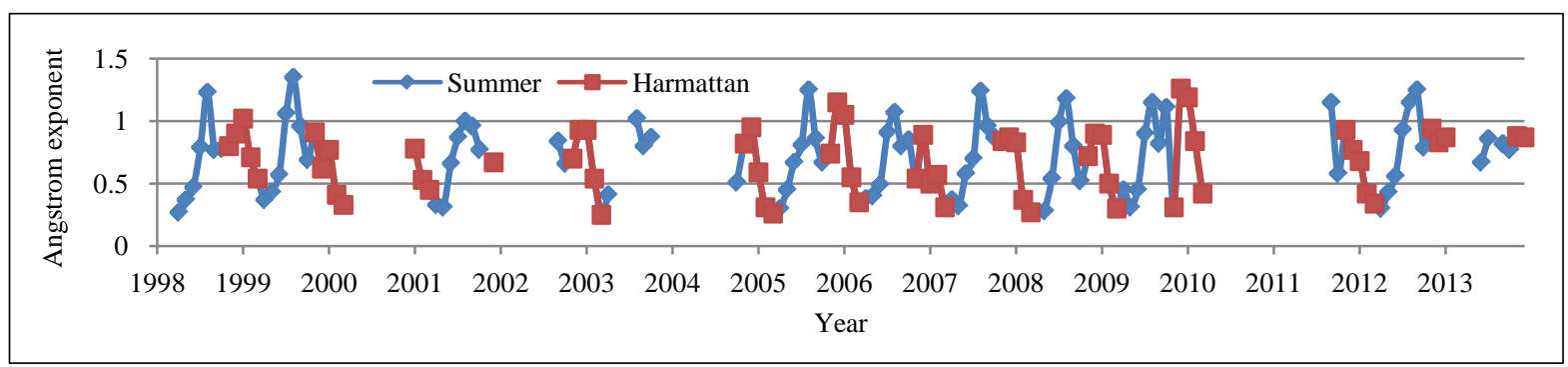

(b)

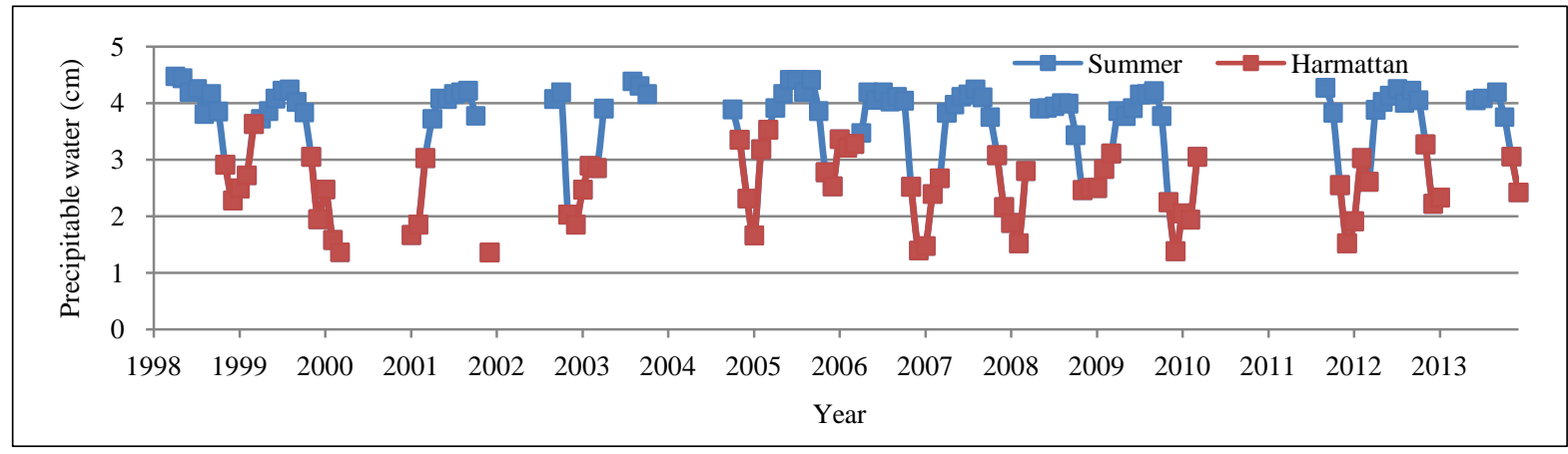

(c)

Figure 2. The monthly variation of Aerosol properties over a period of 16 years at Ilorin, Nigeria. (a) AOD_440; (b) Angstrom_440 - 870; (c) Precipitable water.

On the annual scale, the minimum value of AOD_440 (0.48) occurs in 1998 when the water content (PW) of the atmosphere was at its peak compared to any other year. While investigating the causes of highest and lowest AODs in the year 1998 and 2000, we found that wet deposition, described as the most efficient process of aerosol removal [5], was maximum (highest PW) during 1998 and lowest (lowest PW) during 2000. As a result of this, only smaller concentration of fine particles is present in the atmosphere as against the concentration of largest particles (lowest angstrom 440 - 870) found in 1998, given rise to the maximum AOD of 1.28 in 2000 . The large variability $( \pm 0.56)$ in the observed AOD values during the year indicates large increase in the concentration of coarse-mode in the atmosphere. However, the variability was low in 2013, resulting from a significant decrease in aerosol concentrations, possibly due to government regulations in the control of aerosol pollution. AOD values were uniformly distributed (0.621 - 0.669) from 2003 to 2009.

The overall and seasonal mean for angstrom $440-870(\alpha)$ are $0.66 \pm 0.36,0.68 \pm 0.34$, and $0.64 \pm 0.37$ respectively. Angstrom ranges from 0.04 to 1.64 and $-0.26-1.87$ on a daily basis in Harmattan and Summer. The majority of the values are generally below 1 (86\%) which signifies the dominance of coarse particles in the region. 
Table 1. Annual mean and standard deviations of AOD_440, angstrom 440 - 870 and precipitable water.

\begin{tabular}{|c|c|c|c|c|c|c|}
\hline Year & AOD (440) & $\begin{array}{l}\text { Standard } \\
\text { deviation }\end{array}$ & Angstrom $_{440-870}$ & $\begin{array}{l}\text { Standard } \\
\text { deviation }\end{array}$ & PW (cm) & $\begin{array}{l}\text { Standard } \\
\text { deviation }\end{array}$ \\
\hline 1998 & 0.484 & 0.295 & 0.709 & 0.266 & 3.822 & 0.318 \\
\hline 1999 & 0.608 & 0.406 & 0.769 & 0.295 & 3.487 & 0.421 \\
\hline 2000 & 1.275 & 0.560 & 0.503 & 0.163 & 1.81 & 0.627 \\
\hline 2001 & 0.742 & 0.582 & 0.666 & 0.267 & 3.286 & 0.415 \\
\hline 2002 & 0.533 & 0.376 & 0.783 & 0.235 & 3.035 & 0.415 \\
\hline 2003 & 0.866 & 0.550 & 0.689 & 0.239 & 3.569 & 0.543 \\
\hline 2004 & 0.712 & 0.333 & 0.76 & 0.22 & 3.187 & 0.487 \\
\hline 2005 & 0.728 & 0.416 & 0.672 & 0.223 & 3.588 & 0.466 \\
\hline 2006 & 0.748 & 0.523 & 0.69 & 0.273 & 3.493 & 0.428 \\
\hline 2007 & 0.769 & 0.518 & 0.678 & 0.264 & 3.332 & 0.443 \\
\hline 2008 & 0.740 & 0.516 & 0.673 & 0.209 & 3.125 & 0.388 \\
\hline 2009 & 0.793 & 0.458 & 0.704 & 0.215 & 3.326 & 0.273 \\
\hline 2010 & 0.978 & 0.387 & 0.817 & 0.193 & 2.347 & 0.503 \\
\hline 2011 & 0.549 & 0.329 & 0.858 & 0.213 & 3.043 & 0.405 \\
\hline 2012 & 0.795 & 0.589 & 0.718 & 0.232 & 3.468 & 0.448 \\
\hline 2013 & 0.593 & 0.318 & 0.82 & 0.287 & 3.417 & 0.387 \\
\hline
\end{tabular}

The remaining 14\% that are above 1 occur mostly during the Summer season. However, Angstrom values present almost similar pattern of fluctuation in each season, even though some few high values are visible during Summer period compared to Harmattan, indicating the dominance of coarse particles in each season. This means that, although the presence of rain decreases the concentrations seasonally, the region has been dominated by larger aerosol year after year which is either marine aerosol or dust. Angstrom 440 - 870 values range from 0.2 to 1.35 on a monthly basis while 0.50 to 0.86 on an annual scale. The water content in the atmosphere (Precipitable water PC) as shown in Figure 2(c) occurs more frequent at lower values $(1.36-3.63 \mathrm{~cm})$ during Harmattan which correspond to very high aerosol concentrations. It increases significantly during Summer which influences the removal of larger aerosol from the atmosphere. PW varies from 0.57 to 5.10 daily, 1.36 to 4.48 monthly and 1.81 to 3.82 on an annual basis.

\subsection{Seasonal Variation of Aerosol Properties Using Relative Frequency Distribution Patterns}

For a better understanding of aerosol properties over the study site, the overall and seasonal relative frequency distributions of AOD_440, $\alpha \_440$ - 870 and PW in the atmosphere are plotted in Figure 3. The wavelength dependence of these parameters makes it possible for many scientists who use them in characterising aerosol properties [15] [21] [28] as adopted in this study. This is aim at revealing how the distribution of Optical Properties of aerosols changes with the seasons, which can help in identifying the major aerosol types [17] [22]. From Figure 3(a) (blue), overall AOD occurs most frequent at approximately 0.3 with majority of the populations distributed between the range of 0.1 to 1.6 (95\% frequency of occurrence), which signifies high aerosol loading in the atmosphere in most of the day. These levels of turbidity are influenced by seasonal variation. For instance, during Harmattan period, the frequency histogram of both AOD_440 and AOD_870 are quite broad with values occurring even at above 3.3. On many occasions (about 52 times throughout the period), AOD was greater than 2. Up to $97 \%$ of the AOD_440 observations are found to be above $0.3 \%$ and $0.2 \%$ are below 0.2 . The AOD_440 below 0.15 (pure marine) occurs only once throughout the study period. For the corresponding AOD_870, up to 


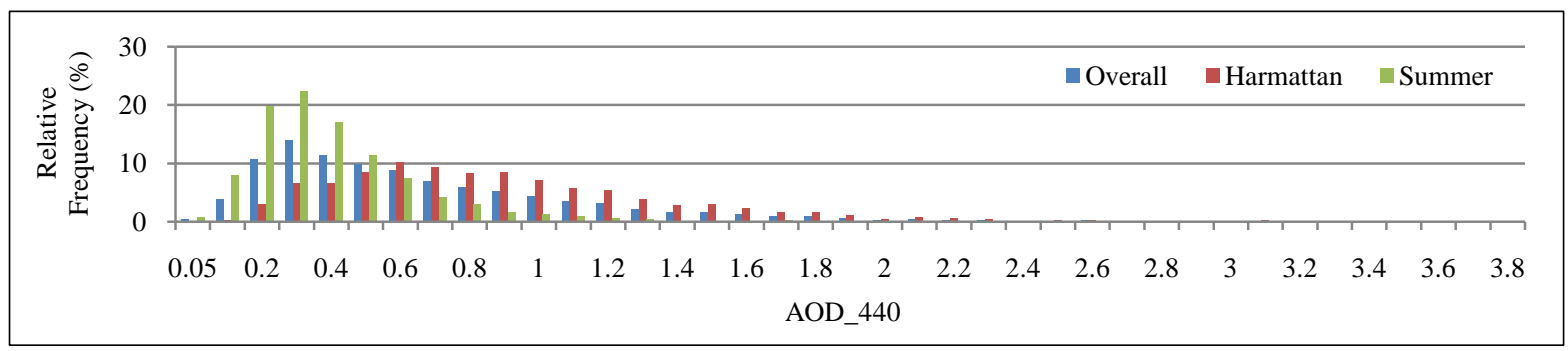

(a)

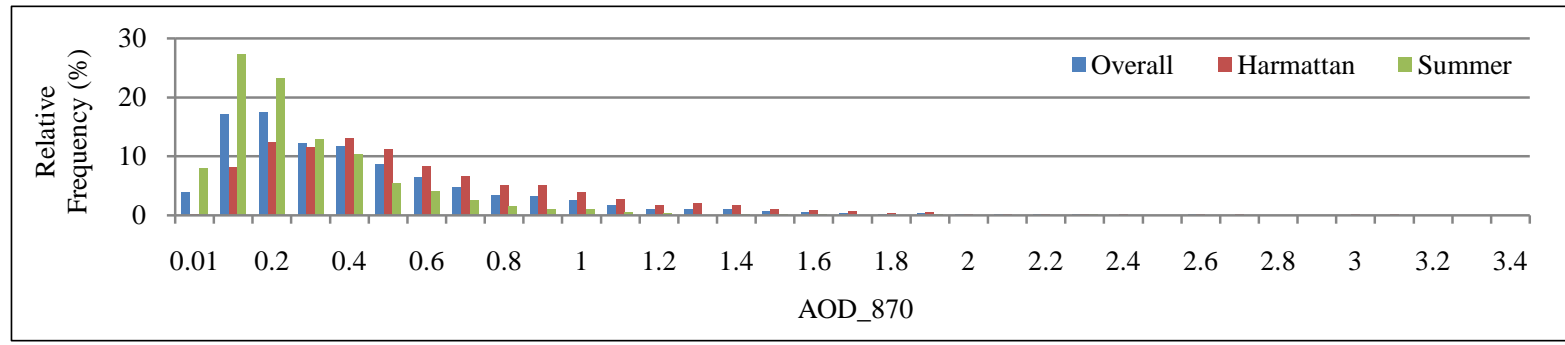

(b)

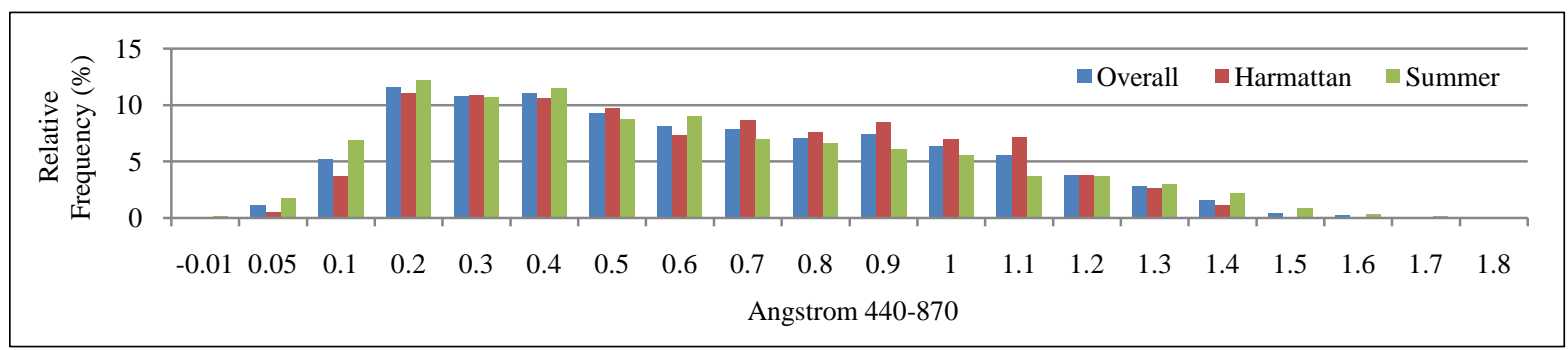

(c)

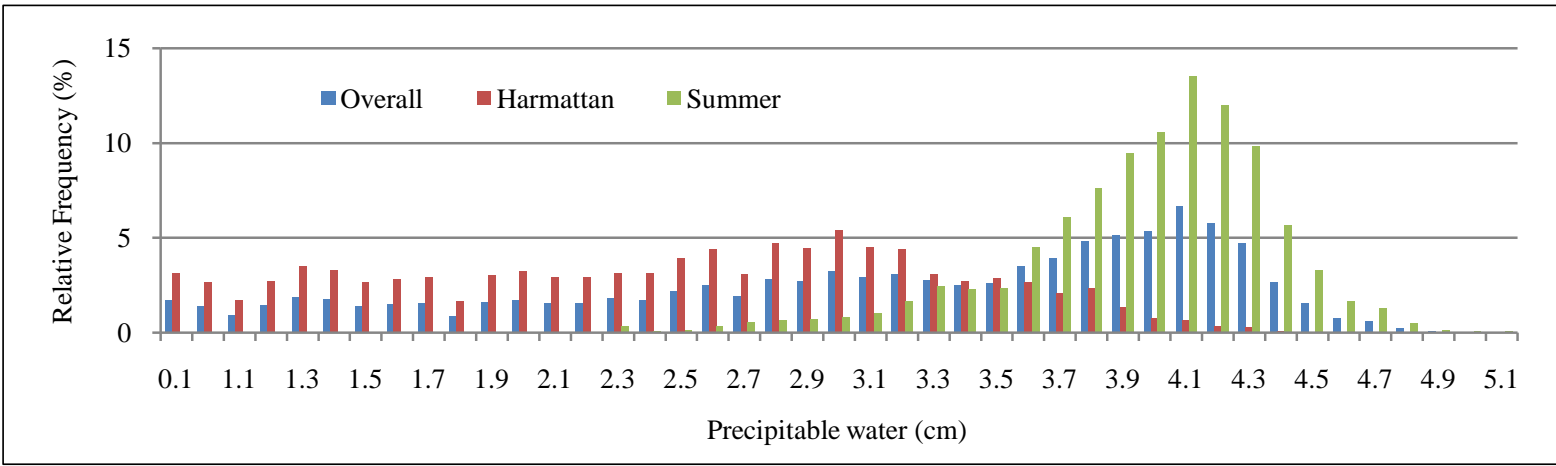

(d)

Figure 3. Relative frequency of occurrence of overall and seasonal AOD_440, angstrom 440 - 870 and precipitable water.

$79 \%$ of the data are above $0.3 \%, 8.4 \%$ are above 0.2 , and only $3.3 \%$ are below 0.15 . The occurrence of high AOD (above 0.3 ) indicates that the area is highly polluted during Harmattan related to transported dust aerosols from Sahara. It may also characterize the presences of continental and biomass burning aerosol. Within this period, large fraction ( $78 \%$ and $72 \%$ ) of the daily AOD_440 and AOD_870 observation are almost equally distributed in the ranges of $0.3-1.2$ and $0.1-0.7$ which can be related to constant heavy pollution. However, during Summer, the frequency of AOD_440 above $0.3 \%$ is $71 \%$ of the total observations, whereas $8.9 \%$ are below 0.2 . The frequency of AOD_440 below $0.15 \%$ is 3.1\%. For AOD_870, the frequency of above $0.3 \%$ is $41 \%$, $35.3 \%$ is however below 0.2 and only $22.1 \%$ occurs below 0.15 . At very few occasions during Summer (5 times), AOD greater than 2 was observed. This decrease in the frequency of occurrence of high AOD (above 0.3) indi- 
cates that Summer is less polluted compared to Harmattan. This decreased has resulted in increased frequency of AOD from 0 to 2 which can be related to possible contribution from marine aerosol to the study site. However, large numbers of high turbidity episode which can be related to dust particles are also present in the Summer. Moreover, relatively less polluted sky (AOD below 0.15 ) occurred at (3.1\%) during Summer because aerosol is washed down compared to Harmattan where it occurs only once. The AOD frequencies histogram during Summer is similar to that in Harmattan except that it appears narrower here, and the majority of the data moved to lower AOD 0.1 - 0.8 (93.1\% and 96\%). Within these values, three noticeable peaks were observed at $0.2-0.4$ for AOD_440 which can be distinguished from those in the other range and season. The high frequency of AOD at 0.1 and 0.5 is also observed. For the AOD_870, frequencies peak at $0.1-0.2$. These multiple peaks indicate the presence of many aerosol populations. Fuyi et al. [15] found that the clearest sky in Kuching occurs during the post-monsoon season, when the majority of the AODs record was distributed within the range of 0.1 to 0.2 . In our study site, the frequencies of occurrence of such AODs were $5 \%$ and $34 \%$ during Harmattan and Summer respectively. The frequencies of AOD below 0.1 (clean air mass) are $0 \%$ during Harmattan and $1.2 \%$ (14 times during Summer, mostly between August and September, with single occurrence in June and October). During this period, angstrom ranges between 1.01 - 1.74 while PW ranges between $4.11-4.65$. Which indicates that only very few days during the Summer are free from the occurrence of coarse mode aerosols (desert dust) [15].

The frequency distribution of angstrom values is broad covering the range of $0.04-1.87$, indicating great number of aerosol type. Majority of these angstrom values lie between $0.1-1.1$ (90\% frequency of occurrence) in all the seasons. About (79\%) in the overall data are below 1, and almost similar situation are observed in Harmattan (78\%) and Summer (81\%). This clearly shows that the region is highly affected by coarse particles, such as dust (Figure 3(b)). This condition can be related to the dry characteristics of weather in Nigeria that gives rise to frequent desert dust outbreak. The highest frequency of angstrom below one during Summer may be due to the significant contribution from coarse mode aerosol other than dust (marine aerosol). The negative angstrom values were observed only twice during the Summer seasons (April 2001 and May 2006). These were found to correspond to the period of Summer highest AODs. During the period, PW was approximately $3.84 \mathrm{~cm}$ in 2001 and $3.64 \mathrm{~cm}$ in 2006 indicating the dryness of the atmosphere [29]. This dry weather is therefore, believed to have favored high aerosol emission, mostly of coarse mode and produced the maximum AOD over the entire period. Higher values of angstrom ranging from 0.9 - 1.2 observed during Harmattan (26\%) compared to Summer (19\%) are mostly related to an undefined aerosol. Distribution of angstrom from 1.3 to 1.6 which represent biomass burning aerosols according to other studies [15] [19] [28] were also found both during both Harmattan (4\%) and Summer (6\%). We firmly believe that this aerosol originate from the local sources (neighboring regions) because Nigeria usually experiences biomass burning activities during Harmattan period when people either preparing land for upcoming rainy seasons or burning for the need of warmer environment due to cold breeze that accompany Harmattan. This burning extends mostly to the Summer season. Although, the biomass burning aerosol might not seem to make any significant contributions, occurring mostly from the extreme northern part of the country. We, however, expect that Harmattan wind can transport this smoke to the study site which together with other aerosol may combine to produce significant mixer.

According to Okulov et al. [29], the atmosphere is said to be humid when PW $>4.0 \mathrm{~cm}$ otherwise it is considered to a dry condition. The fact that only $29 \%$ of the total PW observations exceeds $4.0 \mathrm{~cm}$ implies that most time the atmosphere in Ilorin remains dry, though conditions of humidity over the site varies with season. This is consistent with the observation in Figure 3(c) in which, out of all PW measured during Harmattan only 2.2\% has a value of more than $4.0 \mathrm{~cm}$. These occur mostly in 1999, 2003, 2005, 2006 and only once in 2012. However, during Summer, about 59\% of the frequency of PW is above $4.0 \mathrm{~cm}$ which indicates that dry conditions of the atmosphere in this region do not only occurs during Harmattan alone but that a considerable number of days and month within Summer experience dry conditions that are favorable for dust emission, transport and circulation in the atmospheric column as well.

\subsection{Seasonal Discrimination of Aerosol Types Based on Relationship between AOD and Angstrom Exponent}

Aerosol classification base on AOD and angstrom exponent scatter plot is useful in classifying different aerosol for a particular location through identifying and interpreting the level of density of AOD and angstrom (cluster) in the scatter diagram. The used of AOD revealed the information about the aerosol density in an atmospheric 
column while angstrom gives information about aerosol size distributions. The AOD and angstrom values from the scatter plots can be interpreted together to identify the aerosol types and their frequencies in a particular location quantitatively. These therefore, make regional studies important because very different pattern in AOD against angstrom scatter are observed by different authors from different regions of the world [16] [17] [21]-[24]. It is important to note that the angstrom 440 - 870 is commonly used due to its nearness to the typical size range of aerosol [12] [21]. Several authors [17] [21]-[24] have used this angstrom values (angstrom 440 - 870) against AOD_500 to characterized and classify aerosol in different regions because the two are indicative of turbidity condition and aerosol types. On the other hand, some researchers such as Jalal et al. [18] and Toledano et al. [19] used it (angstrom 440 - 870) against AOD_440 to characterized and classified aerosol in their study sites. To effectively characterize and classify different aerosols types in the Nigerian environment, the threshold criteria provided by Toledano et al. [19] is therefore adopted in our study site. In many literatures, different aerosols classes were identified as dust aerosol (DA), Maritime aerosol (MA), Continental/Urban/industrial aerosol (UIA), Biomass burning aerosol (BMA) and mixed aerosol (simply referred to as MIXA) [11]. According to Toledano et al. [19], the size distrbution are dominated by MA when AOD_440 $<0.2$ and $\alpha \_440-870$ lies between 0 and 2 . As AOD_440 increases above $0.2(0.2-0.35)$ with angstrom $>1.05$ continental/urban/industrial aerosol are said to be dominant. BMA aerosol can also be determine when AOD $>0.35$ and angstrom $>1$.4. However, AOD_870 were used to identify dessert dust when AOD_870 values $>0.11$ and angstrom $<1.05$.

Using the criteria, the scatter plots were extensively analyzed, as shown in Figure 4. The color scales in the plots correspond to the number of observation in a different region defined by AOD and angstrom. Even though, it is established that different scatter plots of angstrom against AOD obtained in different literature owing to different locations and data set makes interpretations of angstrom against AOD difficult [15] [28]. It is obvious from the figures that, angstrom shows decreasing values with increasing AOD which indicates the presences of coarse mode particles, mostly dust [30]. Also observed is the wide range of values of angstrom at low AOD $(\leq 0.4)$ during Summer, indicating the presence of different aerosol types under relatively clear atmospheric conditions which can be used to explain our previous observation in Figure 3(a). Furthermore, the highest number of measurements in the scatter plots for this site is concentrated in the area corresponding to angstrom $440-870(0.1$ to 1.5) and AOD between 0.1 - 1.6, indicating the presence of dust particles. Aerosol from maritime origin and biomass burning with large number of MIXA are observed in this cluster. However, the region correspond to dust aerosol has a very large number of measurement compared to others. There are also large number of measurements concentrated at AOD $>1.6$ which are characterized by angstrom $440-870<1$. This case corresponds to the occurrence of either strong dust activities or heavy pollution event. The study further notes similar pattern of aerosol distribution during Harmattan and Summer seasons (Figure 4(b) and Figure 4(c)) except that majority of the aerosol population corresponding to MIXA and BMA occur during Harmattan and that of maritime and UIA are found in the Summer seasons.

The relative frequencies of these aerosols are shown in Figure 5. The dust class was determined as the highest frequency of occurrence (80.5\%) in the overall data. This could be the result of Nigeria geographical location (being located in sub-Sahara West Africa). The next highest was the MIXA class (9.4\%) likely due to a mixture
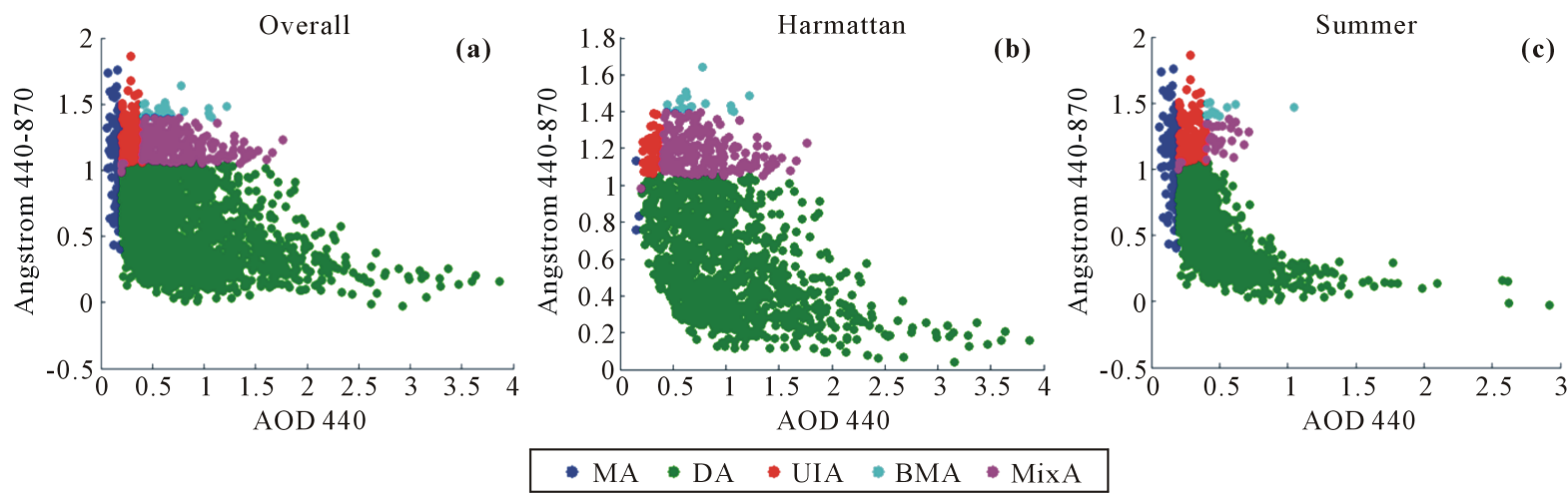

Figure 4. Scatter plot between AOD_440 and Angstrom $440-870$ based on Toledano et al. (2007) for aerosol types discrimination over Ilorin Nigeria ((a) Overall; (b) Harmattan; (c) Summer). 


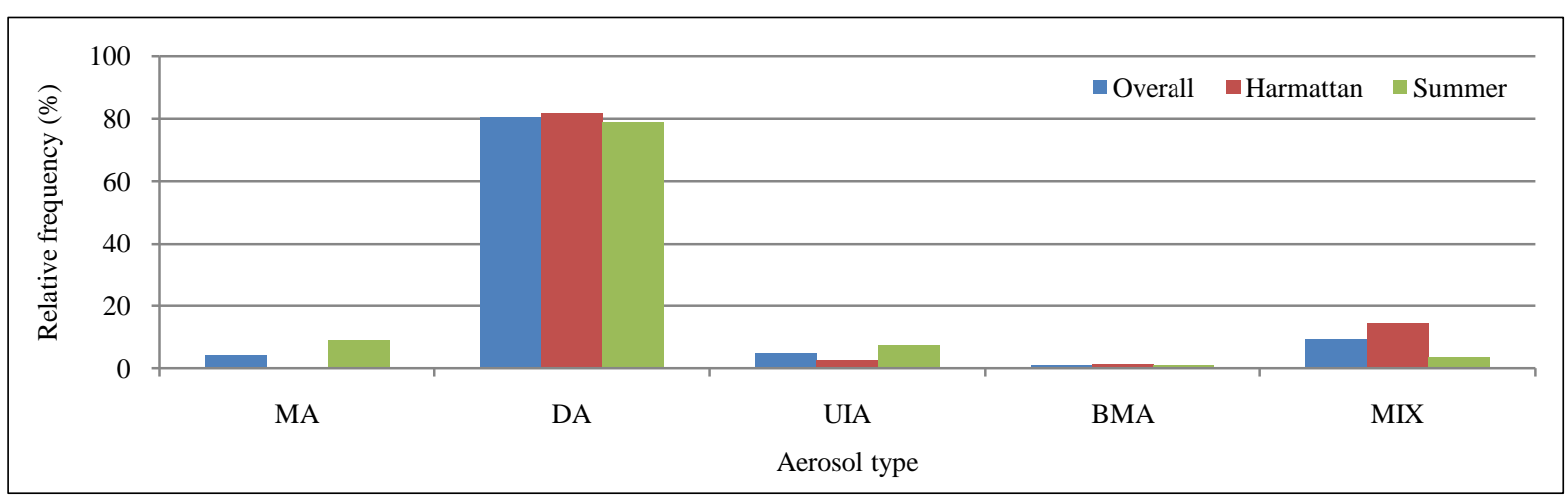

Figure 5. Overall and seasonal classification of aerosol using angstrom-AOD scatter plot based on Toledano et al. (2007).

of desert dust and biomass burning [19]. UIA and MA (4.7\% and 4.3\%) are also some of the major pollutants in Ilorin, Nigeria which was produced by active industrial emission and transport from Atlantic Ocean. The study site was minimally affected by BMA (1.2\%). Nwafor et al. [3] supports these results by suggesting that DA, and UIA, is likely the most common aerosol types in Nigeria. Even though, it is evident from Figure 4 that the frequency of aerosol distributed in Nigeria was highly dependent on seasonal change. However, according to this classification, the dessert aerosols are dominat (82\% and 79\%) in both seasons (Harmattan and Summer). This is consistent with the observation in Figure 3(c), in which about 86\% of the frequency of occurrence of overall and seasonal angstrom values are within the range of $-0.1-1$, indicating that majority of the aerosols are dominated by coarse particles such as dust. These were further observed by analyzing the difference in the seasonal frequency of occurrence of angstrom values and found that the differences are not so large, indicating that similar aerosol types dominate both seasons. We believe therefore, that even though the concentrations may vary, homogeneous aerosol dominate both Harmattan and Summer seasons. We also believe that these aerosols are mostly transported from Sahara and neighboring sources. It was also observed in Figure 3, some noticeable peaks occur at moderately high (0.7 - 1.1) angstrom values during Harmattan, lower (0.2 - 0.4 and 0.6) during Summer. We relate this to a large amount of aerosols that cannot be determined (MIXA) which signifies the occurrence of different aerosol species. These results are clearly seen in Figure 5 which reveals that during Harmattan, MIXA is the second dominant (14\%) followed by UIA (2.4\%) and least BMA (1.2\%) as a result of trans-boundary aerosols from the neighboring regions in the north. MA was observed only 3 times possibly due to drier conditions. During Summer, different aerosol species are found related to the multiple peaks which can also be clearly seen in Figure 5 (blue), where MA (9\%) obtained is the second dominant aerosols during the Summer. This is attributed to the South-westerly trade wind which transports the marine aerosol from Atlantic Ocean as well as the impact of rainy season, UIA and MIXA were about 7, and 4\%, respectively. BMA (1.2) is the minimum aerosol that occurs over the study site within the period of study due to little amount of trans-boundary aerosol.

Using similar criteria suggested by [3] the analysis was performed on a monthly basis and the results are presented in Table 2. The result obtained shows that the frequencies of dust aerosol are high in Harmattan months and low in the Summer months which are consistent with the pattern of monthly AOD distribution. In particular, during February and March the frequency of occurrence of dust becomes maximum (97.3\% and 99.6\%) because MIXA, being the second most frequent case during Harmattan, occurs mostly in January, November and December $(21.7 \%, 13 \%$, and $30.2 \%)$ of the total cases in each of the months. It is observed that, during the transition periods between Harmattan and Summer (April and October), the frequency of dust occurrence in the atmosphere still remain high (100\% and 82.2\%). In fact, the month of April is characterized by pure dust particles which dominate the atmosphere. MA, UIA and BMA are obviously absent from January to March in our study sites. The little contributions from these aerosols to the total aerosol loading usually occur in November and December. These aerosols are found throughout the Summer seasons except from April to May. The months of lowest AOD (August and September) also correspond to the months of lowest frequency of dust activities. It is also worthy of note that we suspect majority of biomass burning aerosol is associated with dry season burning, as people prepare for rainy season farming, which is very consistence with our result (BMA occurs most frequently in November and December). Maritime aerosols that show high frequency of occurrence during Summer 
Table 2. Monthly discrimination of different aerosol types using AOD and angstrom 440 - 870 over Ilorin Nigeria.

\begin{tabular}{|c|c|c|c|c|c|c|}
\hline \multirow{2}{*}{ Month } & \multirow{2}{*}{ No. Obs. } & MA & DA & UIA & BMA & MIX \\
\hline & & RF (\%) & RF (\%) & RF (\%) & RF (\%) & RF (\%) \\
\hline Jan & 309 & 0.0 & 78.0 & 0.0 & 0.3 & 21.7 \\
\hline Feb & 256 & 0.0 & 97.3 & 0.0 & 0.0 & 2.7 \\
\hline Mar & 249 & 0.0 & 99.6 & 0.0 & 0.0 & 0.4 \\
\hline Apr & 197 & 0.0 & 100.0 & 0.0 & 0.0 & 0.0 \\
\hline May & 203 & 4.4 & 95.6 & 0.0 & 0.0 & 0.0 \\
\hline Jun & 194 & 11.9 & 82.5 & 2.1 & 0.5 & 3.1 \\
\hline Jul & 134 & 14.9 & 60.4 & 13.4 & 3.0 & 8.2 \\
\hline Aug & 85 & 11.8 & 30.6 & 27.1 & 5.9 & 24.7 \\
\hline Sep & 140 & 18.6 & 62.1 & 15.7 & 2.1 & 1.4 \\
\hline Oct & 264 & 8.3 & 82.2 & 8.0 & 0.0 & 1.5 \\
\hline Nov & 285 & 0.7 & 73.7 & 11.2 & 1.4 & 13.0 \\
\hline Dec & 291 & 0.3 & 64.6 & 0.7 & 4.1 & 30.2 \\
\hline Overall & 2607 & 4.3 & 80.5 & 4.7 & 1.2 & 9.4 \\
\hline Winter & 1390 & 0.2 & 81.7 & 2.4 & 1.2 & 14.4 \\
\hline Summer & 1217 & 9.0 & 79.0 & 7.2 & 1.1 & 3.6 \\
\hline
\end{tabular}

are distributed mostly from May to October except in August which can be associated with smaller number of observations as a result of cloud interactions.

\subsection{HYSPLIT_4 Model for Seasonal Flow Patterns of Air as a Means to Identify Aerosol Origin}

A 7-day back trajectory frequency seasonal plot sourced from Hysplit_4 model is presented in Figure 6. From the model, pattern of air flow reaching Ilorin Aeronot site in Nigeria during November 2011-March 2012 Harmattan season and April-October 2012 Summer season were illustrated in terms of percentage average between grounds to a high altitude $(5000 \mathrm{~m})$. It is obvious from the plot that during Harmattan period (November-March), flow of air parcel south-ward from Sahara desert is influenced by north-easterly trade wind. Aerosols observed during this period are therefore, mainly transported from Sahara as well as sources within sahel regions such as Bilma in Niger, and Chad basin and Faya lageau in Chad republic. During this period, biomass burning aerosol along northern part of Nigeria and local area, also transported to the study site eventually mixed with dust to produce significant MIXA. On the other hand, during Summer, the air parcel flow towards the north (Figure 6) from Atlantic Ocean also influences the transport of Maritime aerosol to the study site significantly. Even though the dominant aerosol observed are also from dust (Figure 4, Figure 5 and Table 2) which is related to the position of Nigeria in desert area as well as some local sources. The air parcel is also observed to flow from the north eastern part of Nigeria along Lake Chad, which also contributes to the total dust loading during Summer to the study site. According to Figure 1 and Figure 2, the high turbidity as well as their frequencies (Figure 3(a) and Figure 3(b)) during Harmattan is found to be related to the dust transport and local emission.

To further discriminate the dominant aerosol in this region, the volume size distribution of aerosol were analyzed and plotted in Figure 7. This displayed the overall and seasonal cycle of aerosol volume size distribution over the study period. It is observed that the distribution of aerosol size is bimodal with aerosol volume size distribution for the accumulation of coarse mode particles $(>1.0 \mu \mathrm{m})$ (dust and marine aerosol) being dominant in all seasons. However, the volume of particles $(>1.0 \mu \mathrm{m})$ is 2.35 more in the Harmattan compared to Summer which shows that Harmattan season generally record coarser mode particles than the Summer season. The first 

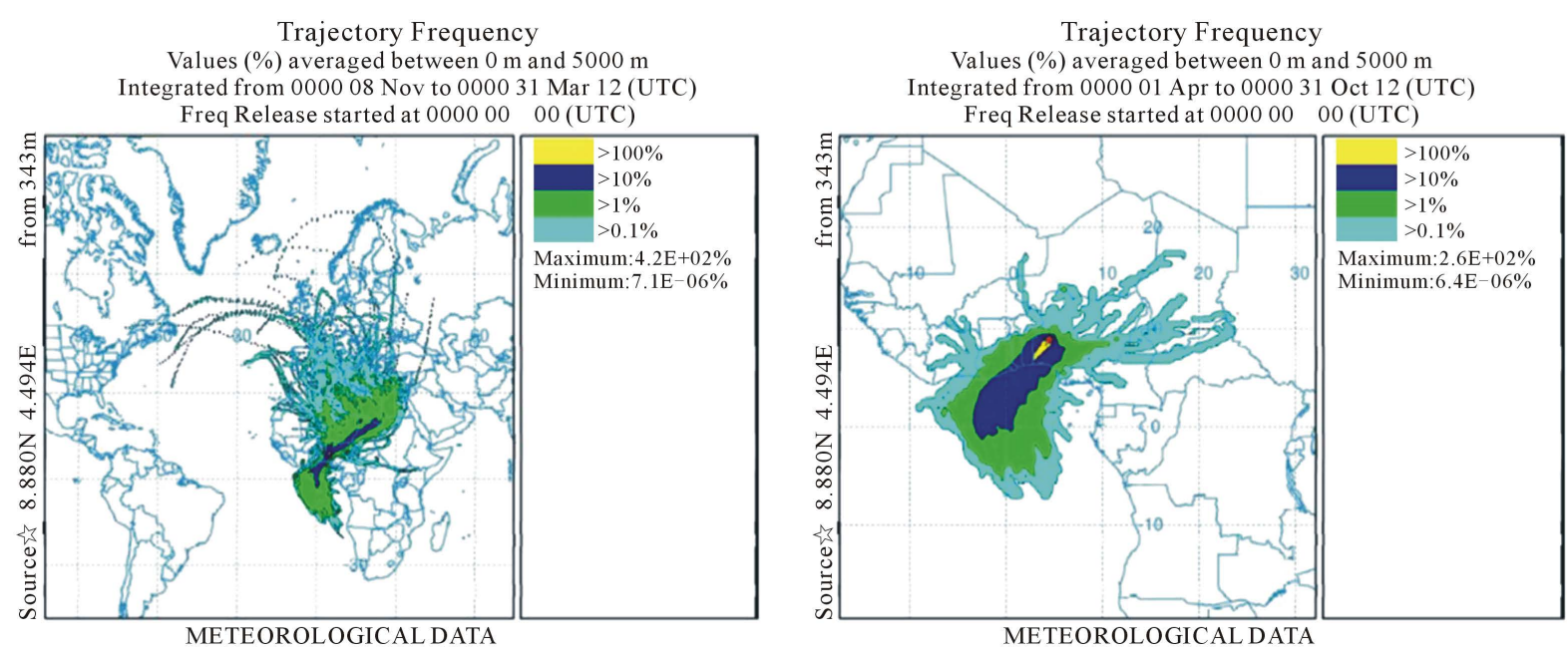

Figure 6. Seven-day back-trajectory frequency seasonal plot by HYSPLIT_4 model during Harmattan and Summer at Ilorin in 2011/2012 (Harmattan and Summer).

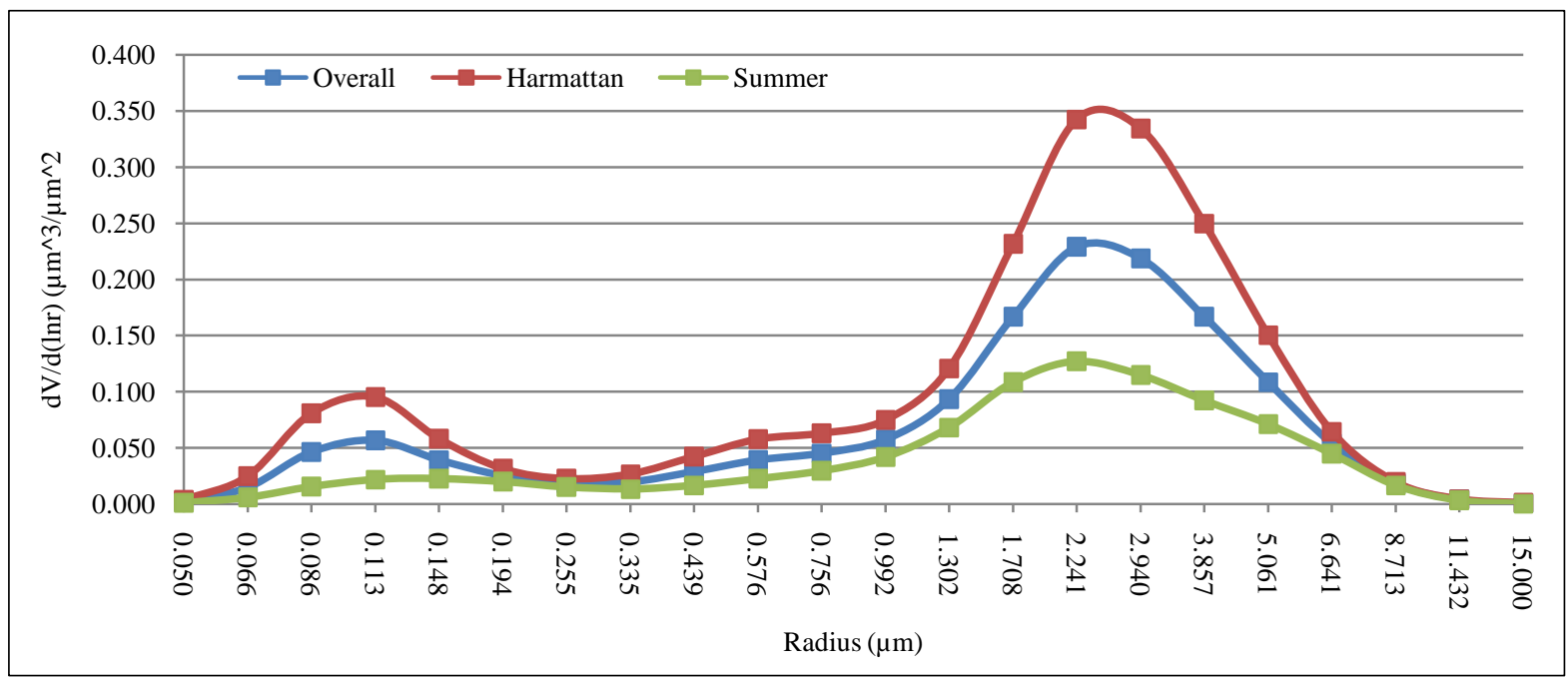

Figure 7. Aerosol volume size distribution at Ilorin Nigeria.

size mode occurs at 0.113 and 0.148 while the second mode occurs at 2.24 for Harmattan and Summer. The volume of the coarse particles is about 3.9 and 4.9 times more than the fine mode particles $(<0.5 \mu \mathrm{m})$. A considerable amount of moderate size particles between 0.5 and $1.0 \mu \mathrm{m}$ are also found (about 2.1 times more in Harmattan than Summer). The large volume of coarse mode particles during both Harmattan and Summer indicates that the atmosphere in this region is affected by coarse mode (dust aerosol). However, the significant high value during Summer supports our finding, that apart from dust aerosol, marine (also coarse mode) is the second dominant aerosol in the region. The observed high volume of moderate size particles during Harmattan also indicates that those aerosols were highly mixed as revealed in Figure 4.

\section{Conclusions}

The long-term (1998-2013) records of aerosol optical depth (AOD) and angstrom exponent $\alpha$, from ground-based Aerosol Robotic Network (AERONET) data, are used to study seasonal variations of aerosol loading, characteristics and type, under different atmospheric conditions for Ilorin Nigeria. The study shows that seasonal variations (Harmattan and Summer) result in different aerosol concentration, characteristics and dominant types. Low AOD values and sensitivity to wavelength occur in the Summer and increase significantly during Saharan dust 
transport season (Harmattan). The average of mean AODs are $0.73 \pm 0.50,0.97 \pm 0.52$ and $0.46 \pm 0.29$ with corresponding mean angstrom of $0.66 \pm 0.36,0.68 \pm 0.34$, and $0.64 \pm 0.37$ for the overall, Harmattan and Summer seasons respectively, though AOD as high as 3.86 was observed during many extreme dessert dust events.

Large percentage of frequency of occurrence of angstrom below 1 (86\%, $78 \%$ and $81 \%)$ for the overall, Harmattan and Summer seasons are observed, which is an indication of occurrence of coarse mode particles such as dust and maritime aerosol. Although, the range of angstrom values in each season shows the presence of many other aerosol types such as biomass burning and urban/industrial aerosols. In all the seasons, dust is identified as the dominant aerosol (82\% and 79\%). MA contributes minimally to the total aerosol load in the study site during Harmattan due to dry weather as shown by low PW but however increases significantly during Summer due to influence of south-westerly trade wind. On the other hand, BMA is generally low in the Summer and increases significantly during biomass burning season (Harmattan). Though, we expect BMA to be the second dominant aerosol type during Harmattan period, the low frequency can be related to the fact that during this period, BMA might have mixed with dust aerosol transported by north-easterly trade wind. This has given rise to a considerable MIXA (14.4\%) being the second obvious feature of the season. Apart from MA, Summer season is also characterized by significant amount of UIA particles in the data, which is believed to be caused by vehicular and industrial activities.

The monthly aerosol discrimination shows that in February and March the frequency of occurrence of dust becomes maximum (97.3\% and 99.6\%) because MIXA, being the secondarily most frequent case during Harmattan, is observed mostly in January, November and December $(21.7 \%, 13 \%$, and $30.2 \%)$ of the total cases in these month. It is observed that, during the transition periods between Harmattan and Summer (April and October), the frequency of dust occurrence in the atmosphere remains high (100\% and $82.2 \%)$. Actually, the month of April is characterized by pure dust particles dominating the atmosphere. MA, UIA and BMA are practically absent from January to March in our study sites, the little contributions from these aerosol to the total aerosol loading usually occurs in November and December. These aerosols are found throughout the Summer seasons except from April to May.

It is instructive to conclude that the size distribution data for the study site show that large volumes of aerosol particles size are enclosed in largely coarse mode range in all seasons. A 7-day back trajectory frequency seasonal plot sourced from the Hysplit Single Particles Lagrangian Integrated Trajectory model (Hysplit_4 model) shows the wind flow trend patterns from the distinct origins of aerosol sources.

\section{Acknowledgements}

The authors gratefully acknowledge the financial support by ESCAP-NASDA (grant no. 304/PFIZIK/650049/ E012). We wish to thank the principal investigator of the Ilorin Aeronet site used in this study. Finally we acknowledge Dr. Tan Fuyi, for the time he devoted at various discussions regarding this work.

\section{References}

[1] Oyem, A.A. and Igbafe, A.F. (2010) Analysis of Atmospheric Aerosol Loading over Nigeria. Environmental Research Journal, 4, 145-156.

[2] Tan, F., Wei, Y.K., Wan, S.H., Yeap, E.C., Lim, H.S. and Abdullah, K. (2015) Investigation of Aerosol Distribution Patterns and Its Optical Properties at Different Time Scale by Using LIDAR System and AERONET. AIP Conference Proceedings, 1657, Article ID: 130001. http://dx.doi.org/10.1063/1.4915232

[3] Nwafor, O.K., Chineke, T.C. and Pinker, R.T. (2007) Seasonal Characteristics of Aerosol Optical Properties at a Sub-Sahara Site. Atmospheric Research, 85, 38-51. http://dx.doi.org/10.1016/j.atmosres.2006.11.002

[4] Balarabe, M., Abdullah, K. and Nawawi, M. (2015) Long-Term Trend and Seasonal Variability of Horizontal Visibility in Nigerian Troposphere. Atmosphere, 6, 1462-1486. http://dx.doi.org/10.3390/atmos6101462

[5] Anuforom, A.C., Akeh, L.E., Okeke, P.N. and Opara, F.E. (2007) Inter-Annual Variability and Long-Term Trend of UV-Absorbing Aerosols during Harmattan Season in Sub-Saharan West Africa. Atmospheric Environment, 41, 15501559. http://dx.doi.org/10.1016/j.atmosenv.2006.08.024

[6] Kehinde, O.O., Ayodeji, O. and Vincent, O.A. (2012) A Long-Term Record of Aerosol Index from TOMS Observations and Horizontal Visibility in Sub-Saharan West Africa. International Journal of Remote Sensing, 33, 6076-6093. http://dx.doi.org/10.1080/01431161.2012.676689

[7] Florence, D.L., Yvon, C. H., Sabine, H. and Pierre, O. (2010) What Do We Know about Effects of Desert Dust on Air 
Quality and Human Health in West Africa Compared to other Regions? Science of Total Environment, 409, 1-8. http://dx.doi.org/10.1016/j.scitotenv.2010.09.025

[8] Chineke, T.C. and Chiemeka, I.U. (2009) Harmattan Particulate Concentration and Health Impacts in Sub-Sahara Africa. The African Review of Physics, 3, 125-135.

[9] Ogunjobi, K., Ajayi, V., Balogun, I., Omotosho, J. and He, Z. (2008) The Synoptic and Optical Characteristics of the Harmattan Dust Spells over Nigeria. Theoretical and Applied Climatology, 93, 91-105. http://dx.doi.org/10.1007/s00704-007-0332-2

[10] Habib, G., Venkataraman, C., Chiapello, I., Ramachandran, S., Boucher, O. and Reddy, M.S., (2006) Seasonal and Interannual Variability in Absorbing Aerosols over India Derived from TOMS: Relationship to Regional Meteorology and Emissions. Atmospheric Environment, 40, 1909-1921. http://dx.doi.org/10.1016/j.atmosenv.2005.07.077

[11] Kaskaoutis, D.G., Kambezidis, H.D., Nastos, P.T. and Kosmopoulos, P.G. (2008) Study on an Intense Dust Storm over Greece. Atmospheric Environment, 42, 6884-6896. http://dx.doi.org/10.1016/j.atmosenv.2008.05.017

[12] Jung, J., Lee, H., Kim, Y.J., Liu, X., Zhang, Y., Gu, J. and Fan, S. (2009) Aerosol Chemistry and the Effect of Aerosol Water Content on Visibility Impairment and Radiative Forcing in Guangzhou during the 2006 Pearl River Delta Campaign. Journal of Environmental Management, 90, 3231-3244. http://dx.doi.org/10.1016/j.jenvman.2009.04.021

[13] Momadou, S.D., Moctar, C. and Amadou, T.G. (2013) Intra-Seasonal Variability of Aerosol and Their Radiative Impacts on Sahel Climate during the Period 2000-2010 Using Aeronet Data. International Journal of Geosciences, 4, 267-273. http://dx.doi.org/10.4236/ijg.2013.41A024

[14] Prospero, J.M., Ginoux, P., Torres, O., Nicholson, S.E. and Gill, T.E. (2002) Environmental Characterization of Global Sources of Atmospheric Soil Dust Identified with the Nimbus7 Total Ozone Mapping Spectrometer (TOMS) Absorbing Aerosol Product. Reviews of Geophysics, 40, 1-31. http://dx.doi.org/10.1029/2000RG000095

[15] Tan, F., Lim, H.S., Abdullah, K., Yoon, T.L. and Holben, B. (2015) Aeronet-Data Based Determination of Aerosol Types. Atmospheric Pollution Research, 6, 682-695. http://dx.doi.org/10.5094/APR.2015.077

[16] Tan, F., Lim, H.S., Abdullah, K., Yoon, T.L. and Holben, B. (2015) Monsoonal Variation in Aerosol Optical Properties and Estimation of Aerosol Optical Depth Using Ground-Based Meteorological and Air Quality Data in Peninsular Malaysia. Atmospheric Chemistry and Physics, 15, 3755-3771. http://dx.doi.org/10.5194/acp-15-3755-2015

[17] Salinas, S.V., Chew, B.N. and Liew, S.C. (2009) Retrievals of Aerosol Optical Depth and Angstrom Exponent from Ground-Based Sun Photomter Data of Singapore. Applied Optics, 48, 1473-1484.

[18] Jalal, K.A., Asmat, A. and Ahmad, N. (2012) Retrieval of Aerosol Optical Depth and Angstrom Exponent for Identification of Aerosols at Kuching, Sarawak. Advanced Materials Research, 518, 5734-5737.

[19] Toledano, C., Cachorro, V.E., Benjon, A., de Frutos, A.M., Sorribas, M., de la Morena, B.A. and Goloub, P. (2007) Aerosol Optical Depth and Ångström Exponent Climatology at El Arenosillo AERONET Site (Huelva, Spain). Quarterly Journal of the Royal Meteorological Society, 133, 795-807. http://dx.doi.org/10.1002/qj.54

[20] Holben, B.N., Eck, T.F., Slutsker, I., Tanre, D., Buis, J.P., Setzer, A., Vermote, E., Reagan, J.A., Kaufman, Y.J., Nakajima, T., Lavenu, F., Jankowiak, I. and Smirnov, A. (1998) AERONET-A Federated Instrument Network and Data Archive for Aerosol Characterizations. Remote Sensing of Environment, 66, 1-16. http://dx.doi.org/10.1016/S0034-4257(98)00031-5

[21] Kaskaoutis, D.G., Kambezidis, H.D., Hatzianastassiou, N., Kosmopolos, P.G. and Badariahnath, K.V.S. (2007) Aerosol Climatology: On the Discrimination of Aerosol Types over Four AERONET Sites. Atmospheric Chemistry and Physics Discusion, 7, 6357-6411. http://dx.doi.org/10.5194/acpd-7-6357-2007

[22] Pace, G., di Sarra, A., Meloni, D., Piacentino, S. and Chamard, P. (2006) Aerosol Optical Properties at Lampedusa (Central Mediterran). Influence of Transport and Identification of Different Aerosol Types. Atmospheric Chemistry and Physics, 6, 697-713. http://dx.doi.org/10.5194/acp-6-697-2006

[23] Smirnov, A., Holben, B.N., Dubovik, O., O’Neill, N.T., Eck, T.F., Westphal, D.L., Goroch, A.K., Pietras, C. and Slustsker, I. (2002) Atmospheric Aerosol Optical Properties in the Persian Gulf. Journal of the Atmospheric Sciences, 59, 620-634. http://dx.doi.org/10.1175/1520-0469(2002)059<0620:AAOPIT>2.0.CO;2

[24] Smirnov, A., Holben, B.N., Dubovik, O., Frouin, R., Eck, T.F. and Slutsker, I. (2003) Maritime Component in Aerosol Optical Models Derived from Aerosol Robotic Network Data. Journal of Geophysical Research-Atmospheres, 108, AAC 14-11-AAC 14-11.http://dx.doi.org/10.1029/2002JD002701

[25] Angstrom, A. (1964) The Parameters of Atmospheric Turbidity. Tellus, 16, 64-76. http://dx.doi.org/10.1111/j.2153-3490.1964.tb00144.x

[26] Draxler, R.R. and Hess, G.D. (1998) An Overview of the HYSPLIT_4 Modelling System for Trajectories, Dispersion on and Deposition. Australian Meteorological Magazine, 47, 295-308.

[27] Oyewole, J.A., Thompson, A.M., Akinpelu, J.A. and Jegede, O.O. (2014) Variation of Rainfall and Humidity in Nige- 
ria. Journal of Environment and Earth Science, 4, 29-37.

[28] Holben, B.N., Tanre, D., Smirnov, A., Eck, T.F., Slutsker, I., Abuhassan, N., Newcomb, W.W., Schafer, J.S., Chatenet, B., Lavenu, F., Kaufman, Y.J., Castle, J.V., Setzer, A., Markham, B., Clark, D., Frouin, R., Halthore, R., Karneli, A., O’Neill, N.T., Pietras, C., Pinker, R.T., Voss, K. and Zibordi, G. (2001) An Emerging Ground Based Aerosol Climatology: Aerosol Optical Depth from AERONET. Journal of Geophysical Research-Atmospheres, 106, 12067-12097. http://dx.doi.org/10.1029/2001JD900014

[29] Okulov, O., Ohvril, H. and Kivi, R. (2002) Atmospheric Precipitable Water in Estonia, 1990-2001. Boreal Environment Research, 7, 291-300.

[30] Ogunjobi, K.O., He, Z., Kim, K.W. and Kim, Y.J. (2004) Aerosol Optical Depth during Episodes of Asian Dust Storms and Biomass Burning at Gwangju, South Korea. Atmospheric Environment, 38, 1313-1323.

http://dx.doi.org/10.1016/j.atmosenv.2003.11.031 